\title{
Association between the miRNA signatures in plasma and bronchoalveolar fluid in respiratory pathologies
}

\author{
Sonia Molina-Pinelo ${ }^{a}$, Rocío Suárez ${ }^{\mathrm{a}}$, María Dolores Pastora ${ }^{\mathrm{a}}$ Ana Nogal ${ }^{\mathrm{a}}$, Eduardo Márquez-Martín ${ }^{\mathrm{b}}$, \\ José Martín-Juan $^{\mathrm{b}}$, Amancio Carnero ${ }^{\mathrm{c}, \mathrm{d}}$ and Luis Paz-Ares ${ }^{\mathrm{a}, *}$ \\ ${ }^{a}$ Molecular Oncology and New Therapies Group, Department of Medical Oncology, University Hospital Virgen del \\ Rocío, Instituto de Biomedicina de Sevilla, Seville, Spain \\ ${ }^{\mathrm{b}}$ Respiratory Disease Medical and Chirurgical Unit, University Hospital Virgen del Rocío, Seville, Spain \\ ${ }^{\mathrm{c}}$ Molecular Biology of Cancer Group, Instituto de Biomedicina de Sevilla, Seville, Spain \\ ${ }^{\mathrm{d}}$ Consejo Superior de Investigaciones Científicas, Spain
}

\begin{abstract}
The identification of new less invasive biomarkers is necessary to improve the detection and prognostic outcome of respiratory pathological processes. The measurement of miRNA expression through less invasive techniques such as plasma and serum have been suggested to analysis of several lung malignancies including lung cancer. These studies are assuming a common deregulated miRNA expression both in blood and lung tissue. The present study aimed to obtain miRNA representative signatures both in plasma and bronchoalveolar cell fraction that could serve as biomarker in respiratory diseases. Ten patients were evaluated to assess the expression levels of 381 miRNAs. We found that around 50\% miRNAs were no detected in both plasma and bronchoalveolar cell fraction and only $20 \%$ of miRNAs showed similar expression in both samples. These results show a lack of association of miRNA signatures between plasma and bronchoalveolar cytology in the same patient. The profiles are not comparable; however, there is a similarity in the relative expression in a very small subset of miRNAs (miR-17, miR-19b, miR-195 and miR-20b) between both biological samples in all patients. This finding supports that the miRNAs profiles obtained from different biological samples have to be carefully validated to link with respiratory diseases.
\end{abstract}

Keywords: miRNA profile, RT-qPCR, plasma and bronchoalveolar fluid cytology, respiratory disease

\section{Introduction}

There is a growing interest in the identification of new biomarkers for diagnosis in early stage, progression and treatment response in lung diseases such as chronic obstructive pulmonary disease or lung cancer $[1,2]$. Nowadays, increasing evidence supports the use of microRNAs (miRNAs) as disease-specific biomarkers [3]. The discovery of miRNAs has revealed an unexpected level of gene expression regulation by

* Corresponding author: Luis Paz-Ares, MD, PhD, Service of Medical Oncology Hospital Universitario Virgen del Rocío, Manuel Siurot s/n. 41013 Seville, Spain. Tel.: +34 955 013414; Fax: +34 955013 292; E-mail: luis.pazares.sspa@juntadeandalucia.es. interacting with messenger RNA [4,5]. MicroRNAs are small non-coding sequences of RNA, approximately 21 to 25 nucleotides long which expression may vary according to cell type, specific tissue or differentiation status [6-9]. The sequences of miRNAs regulate gene expression at the post-transcriptional level by base-pairing with target mRNA molecules [10]. Thus, miRNAs play a pivotal role in a wide range of human diseases including cancer [11-14].

MicroRNAs appear to be well preserved in archival collections of both formalin-fixed and frozen tissues $[15,16]$. The identification of new miRNAs as diagnostic or predictive markers is therefore based in the differential presence of these molecules. In addition, several recent reports show circulating miRNAs 
Table 1

Summary of patients' characteristics

\begin{tabular}{cccl}
\hline Patient & Sex & Age, years & Clinical diagnostic \\
\hline 385 & Female & 60 & Adenocarcinoma \\
435 & Male & 74 & Interstitial lung disease \\
460 & Male & 50 & Healthy \\
505 & Female & 68 & Adenocarcinoma \\
514 & Male & 55 & Adenocarcinoma \\
539 & Female & 61 & Healthy \\
557 & Male & 72 & Interstitial lung disease \\
599 & Male & 54 & Adenocarcinoma \\
729 & Male & 68 & Adenocarcinoma \\
784 & Male & 59 & Adenocarcinoma \\
\hline
\end{tabular}

in biological fluids such as sputum, serum and plasma, among others [17-19], which are easy to collect in a relatively non invasive fashion. MicroRNAs in body fluids can be protected from endogenous RNase activity in exosomes, helping to transfer genetic material in the human body $[17,20]$. However, up to date there are not studies showing a correlation between the expression of miRNAs in different fluid/ tissues of the same patient.

In respiratory diseases the identification of miRNAs in bronchoalveolar fluid cytology or in plasma are procedures less invasive than lung tissue biopsy. To date however, there are no previous studies reporting the comparison of bronchoalveolar fluid cytology-derived miRNA profiles with those obtained from plasma. Also, broncoalveolar fluid is more complicated to collect in patients than blood samples, which are routinely taken. However, is reflected in plasma the status of miRNA signatures present in the bronchoalveolar cytology? We have explored this point in order to find a new, sensitive, and noninvasive method to obtain a biomarker in peripheral blood for respiratory diseases.

To that end, we have compared circulating plasma miRNA with the bronchoalveolar cell fraction-derived miRNA patterns from the same patients using a RTqPCR assay. We have compared the expression levels of miRNAs in ten patients with several lung diseases.

\section{Materials and methods}

\subsection{Patients and clinical specimens}

We assessed global miRNAs expression from ten patients who had required flexible bronchoscopy for diagnostic reasons. The characteristics of the patients are shown in Table 1 . These patients $(7$ men and 3 women) had a median age of 60.5 [range, 54.7-69.0] years. Of the 10 patients diagnosed by bronchoscopy, two of them showed not respiratory disease, two had interstitial lung disease, and six had lung adenocarcinoma stage III or IV. We collected the bronchoalveolar cell fraction, and at the same time collected peripheral blood samples to obtain plasma. Written consent was obtained from the all patients involved in this study. This research was approved by the Ethic Committee of the Hospital and conforms with the Declaration of Helsinki.

Peripheral blood samples were collected in EDTA tubes and centrifuged for $10 \mathrm{~min}$ at $1800 \mathrm{~g}$ at $4^{\circ} \mathrm{C}$. The plasma fractions were aliquoted into new tubes, and stored at $-80^{\circ} \mathrm{C}$ for later RNA isolation. MicroRNA samples did not show any tendency to degradation, as previously described [21]. In parallel, subjects were prepped with a combination of topical anesthesia $(20 \%$ benzocaine spray to pharynx plus $2 \%$ topical lidocaine as needed) and conscious sedation using midazolam according to institutional guidelines. Bronchoalveolar fluid samples were obtained by instillation and aspiration of 40 to $60 \mathrm{ml}$ aliquots of $0.9 \%$ sterile saline in the bronchopulmonary segment. Recovered fluid was immediately passed through a $100-\mu \mathrm{m}$ sterile nylon filter (Becton Dickinson, San Jose, CA) to remove mucus. The bronchoalveolar fluid was centrifuged at $1800 \mathrm{~g}$ and $4{ }^{\circ} \mathrm{C}$ for $10 \mathrm{~min}$. The cell pellet from these samples was washed twice in PBS and frozen as a dry pellet at $-80^{\circ} \mathrm{C}$ for later RNA isolation.

\subsection{RNA isolation}

Total RNA containing small RNA was extracted from plasma by Trizol LS Reagent and from bronchoalveolar cell fraction by Trizol Reagent (Invitrogen, Carlsbad, CA). The total RNA yield was determined using a Nanodrop ND-1000 spectrophotometer (Nanodrop Tech, DE, USA). The quality of the samples was assessed by RT-qPCR analysis of the endogenous control miR-16 using TaqMan ${ }^{\circledR}$ MicroRNA Assays (Applied Biosystems, CA, USA) in bronchoalveolar fluid cytology and plasma.

\section{3. $R T-q P C R$ assay}

Mature human miRNA expression was detected and quantified by using the TaqMan ${ }^{\circledR}$ Low Density Arrays (TLDA) based on Applied Biosystems' 7900 HT Micro Fluidic Cards (Applied Biosystems, CA, USA) according to the manufacturer's instructions. TaqMan ${ }^{\circledR}$ Human MicroRNA A Array v2.0 contained a total of 384 TaqMan ${ }^{\circledR}$ MicroRNA Assays to enable accurate 

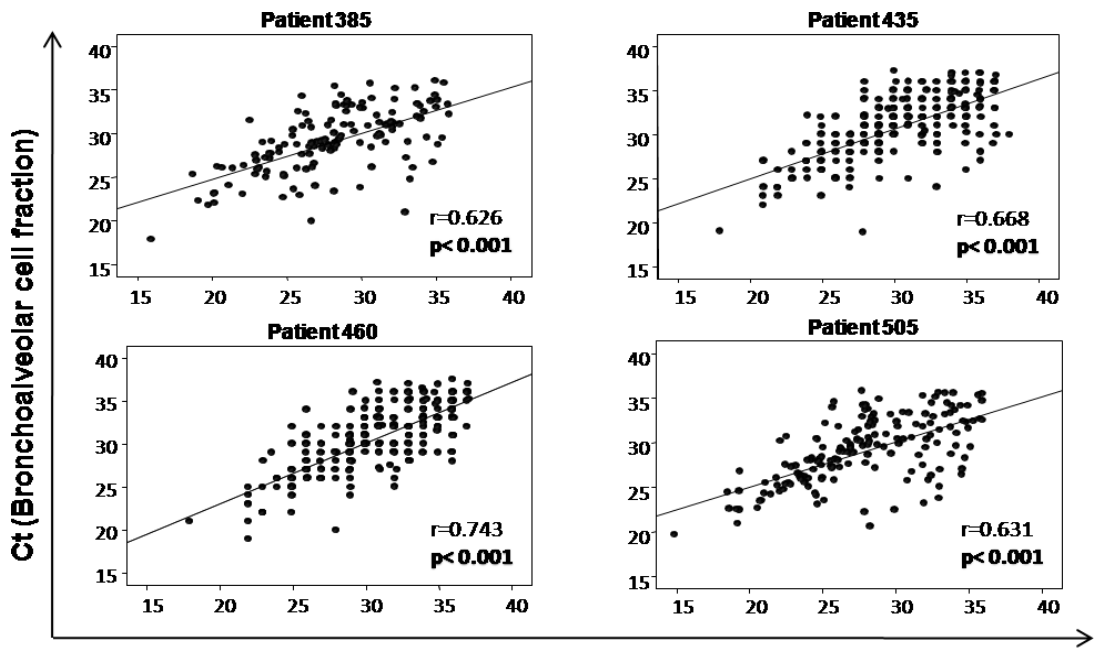

Ct (Plasma)

Fig. 1. Pearson's correlation between the miRNA Ct values of plasma and bronchoalveolar cell fraction.

quantity of 381 human microRNAs, all cataloged in the miRBase database. TLDAs were performed in a two-step process: briefly during the first step, $450 \mathrm{ng}$ of total RNA were reverse transcribed using Megaplex RT Primers and the TaqMan miRNA reverse transcription kit in a total volume of $7.5 \mu \mathrm{l}$. The $7.5 \mu \mathrm{l}$ reactions were incubated in a G-Storm Thermal Cycler (Gene Technologies, Essex, UK) for $2 \mathrm{~min}$ at $16^{\circ} \mathrm{C}, 1 \mathrm{~min}$ at $42^{\circ} \mathrm{C}$, and $1 \mathrm{~min}$ at $50^{\circ} \mathrm{C}$ during 40 cycles, held $5 \mathrm{~min}$ at $85^{\circ} \mathrm{C}$, and then kept at $4{ }^{\circ} \mathrm{C}$. In the second step, $6 \mu \mathrm{L}$ of cDNA sample and TaqMan Universal PCR master mix were loaded in fill ports on the TLDA microfluidic card. The card was briefly centrifuged for $1 \mathrm{~min}$ at $280 \mathrm{~g}$ to distribute samples in the multiple wells connected to the fill ports and then sealed to prevent wellto-well contamination. The reactions were incubated in a 384-well plate at $50^{\circ} \mathrm{C}$ for $2 \mathrm{sec}$ and $94.5^{\circ} \mathrm{C}$ for $10 \mathrm{~min}$, followed by 40 cycles of $30 \mathrm{sec}$ at $97^{\circ} \mathrm{C}$ and $1 \mathrm{~min}$ at $59^{\circ} \mathrm{C}$. The followed workflow is represented in supplementary Fig. S1.

\subsection{Analysis of miRNA expression}

Expression of target miRNAs was normalized in relation to expression of miR-16. One non human miRNA as a negative control was carried out in each experiment. Finally, the cards were processed and analyzed on an ABIPrism 7900 HT Sequence Detection System. Cycle threshold $(\mathrm{Ct})$ values were calculated using the SDS software v.2.3 using automatic baseline settings and a threshold of 0.2. Pearson correlation test was used to analyze the correlations between the miRNA Ct values of plasma and bronchoalveolar cell fraction. Correlations were performed with the SPSS Software (Statistical Package for the Social Sciences version 17.0; SPSS, Inc, Chicago, IL). Relative quantification of miRNA expression was calculated with the $2^{-\Delta \Delta C t}$ method (Applied Biosystems user bulletin no. 2 (P/N 4303859)). MiRNA differences in expression was defined arbitrarily as a 5-fold variation between biological specimens of the same patient. Our data on expression of miRNAs has been published in a public repository that archives experimental data of expression profiling of miRNAs like Gene Expression Omnibus (GEO), database number: GSE33045 (http://www.ncbi.nlm.nih.gov/geo).

\section{Results}

\subsection{Correlation of global miRNA profiling between plasma and bronchoalveolar fluid cytology}

To determine the degree of correlation between the expression levels of $381 \mathrm{miRNAs}$ of plasma samples and bronchoalveolar cell fraction, the miRNA Ct values of plasma were compared with respect to the $\mathrm{Ct}$ values of bronchoalveolar cytology of the same patient in 10 patients. Pearson's correlation factors were in a range between 0.568 and 0.794 , with p-values lower than 0.001 for all patients (Fig. 1; supplementary Fig. S2). We analyzed percentage of miRNAs expressed in plasma and bronchoalveolar cell fraction. We found that from $35.8 \%(\mathrm{~N}=136)$ to $45.4 \%(\mathrm{~N}=172)$ of miRNAs 


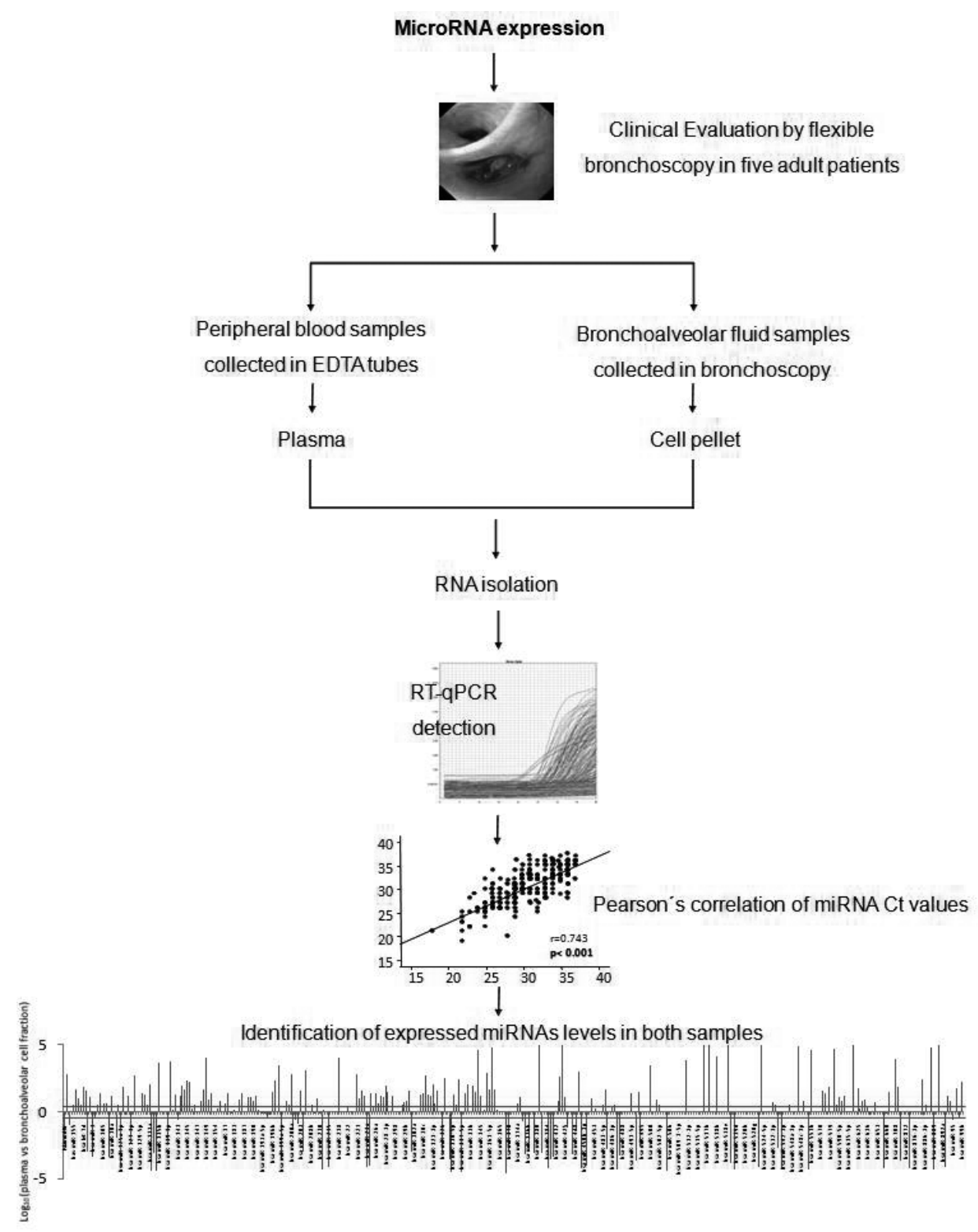

Fig. S1. Followed flow-work for the identification of microRNA expression profile in plasma versus bronchoalveolar fluid cytology.

were not expressed either in plasma or bronchoalveolar cell fraction. Only $55 \%$ of the 381 studied miRNAs were detected in one of both samples. Of these detected miRNAs from $3.7 \%(\mathrm{~N}=14)$ to $14.5 \%(\mathrm{~N}=55)$ were only expressed in plasma and from $5.5 \%(\mathrm{~N}=$ $21)$ to $19.4 \%(\mathrm{~N}=74)$ were only expressed in bronchoalveolar cell fraction from the same patient (Fig. 2; supplementary Fig. S3). There was a lower specific miRNA expression in plasma samples for all patients. Therefore, we found that only around 50\% miRNAs were directly comparable between both samples.

\subsection{Comparison of microRNA relative expression in plasma versus bronchoalveolar cell fraction of the same patient}

To determine the relative expression $(\Delta \mathrm{Ct})$ of individual miRNAs, we selected miR-16 for normalization (miR-16 is commonly used as a reference miRNA both in serum and plasma) [22]. Furthermore, we detected that the absolute $\mathrm{Ct}$ values for miR-16 remained constant both in plasma and bronchoalveolar cell fraction (data not shown). Therefore, the $\Delta \mathrm{Ct}$ values (assays 

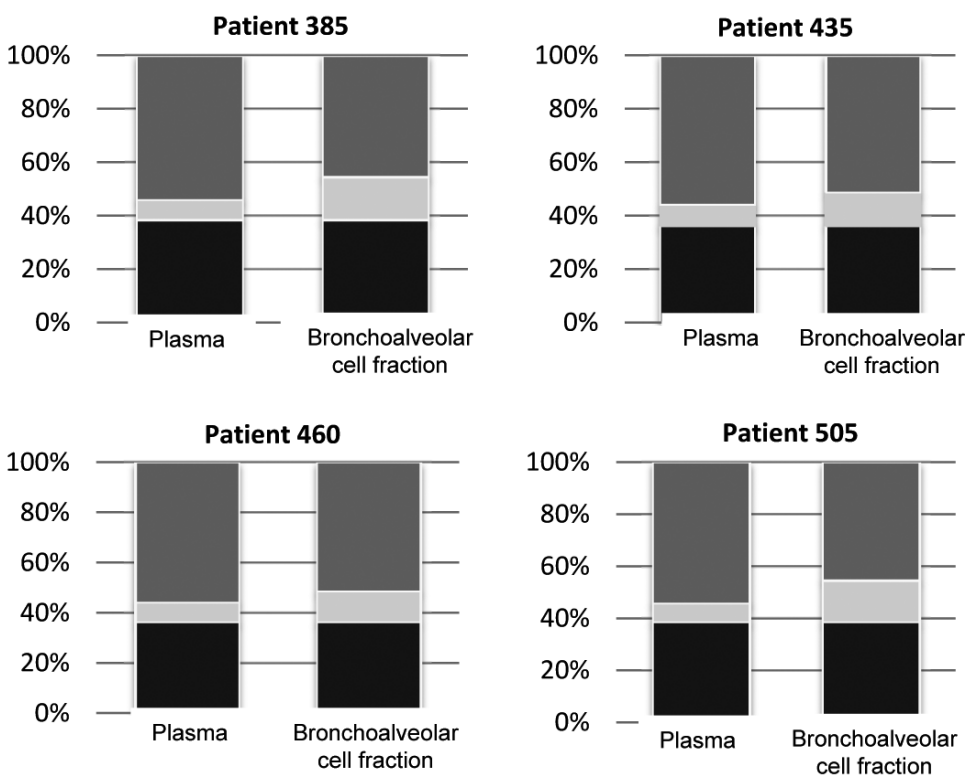

MicroRNAs not expressed neither in plasma nor in bronchoalveolar cell fraction.

$\square$ MicroRNas not expressed in a specimen.

MicroRNas expressed in plasma and/or bronchoalveolar cell fraction.

Fig. 2. Percentage of miRNAs expressed in plasma and bronchoalveolar cell fraction.

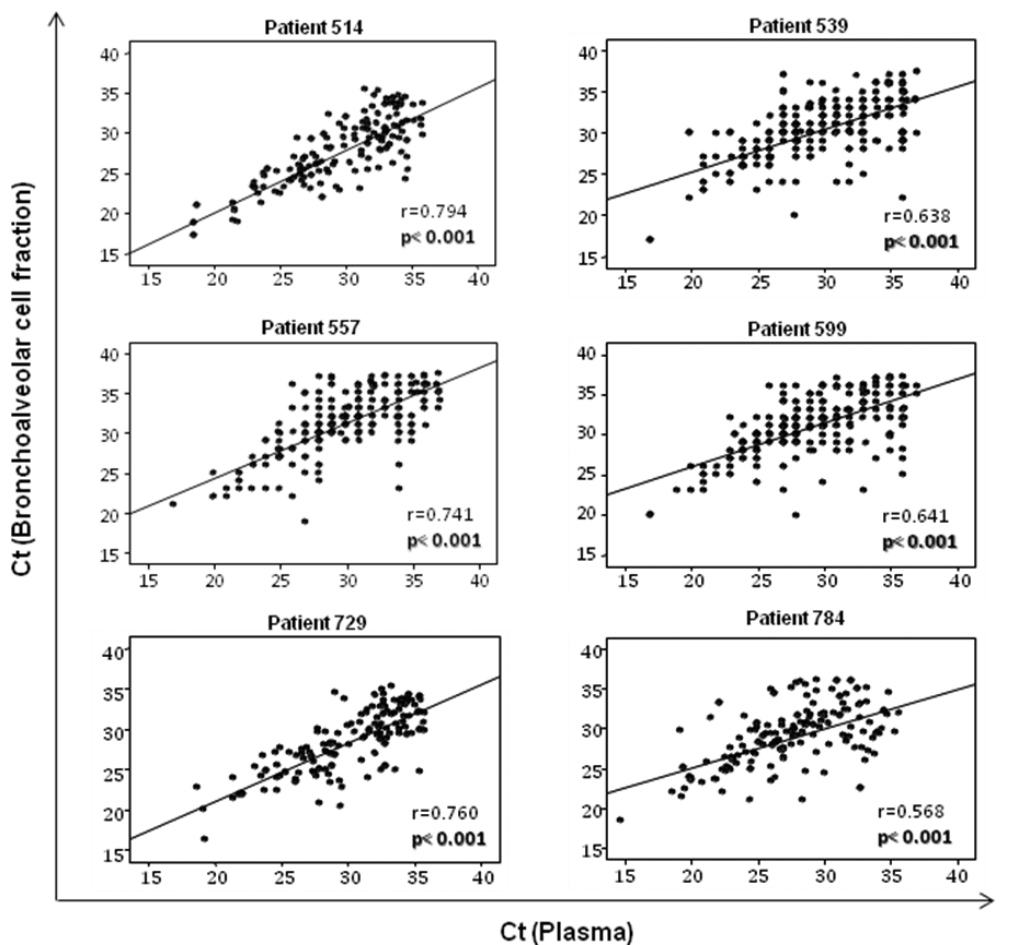

Fig. S2. Pearson's correlation between the miRNA Ct values of plasma and bronchoalveolar cell fraction. 


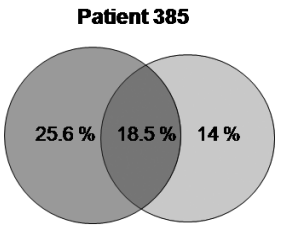

Patient 460

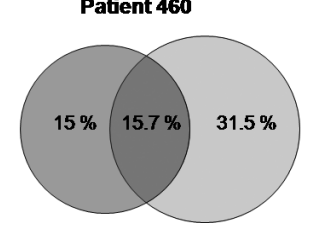

Patient 435

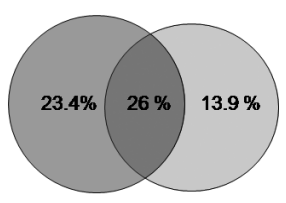

Patient 505

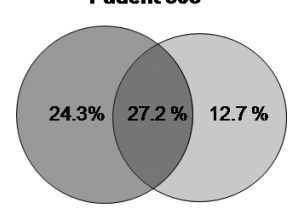

MicroRNAs without expression differences both in plasma

and bronchoalveolar cell fraction

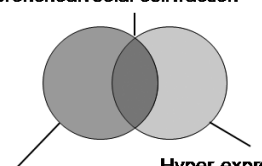

Hyper-expressed miRNAs in

Hyper-expressed miRNAs in plasma

Fig. 3. Percentage of miRNA expression in plasma versus bronchoalveolar cell fraction.
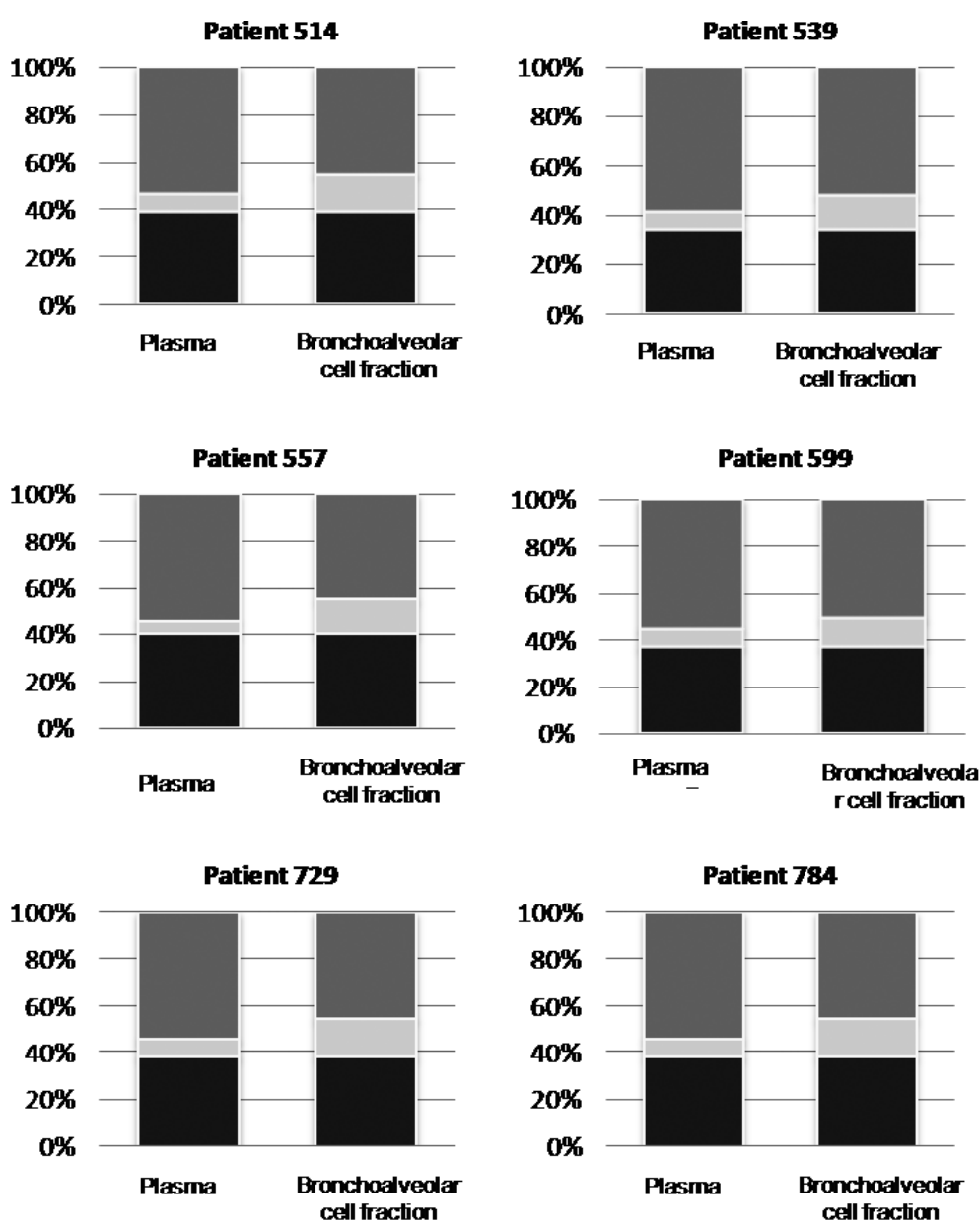

- MicroRNAs notexpressed neither in plasma nor in bronchoalveolarcell fraction.

MicroRNas notexpressed in a specimen.

4 MicroRNas expressed in plasma and/orbronchoalveolarcellfraction.

Fig. S3. Percentage of miRNAs expressed in plasma and bronchoalveolar cell fraction. 


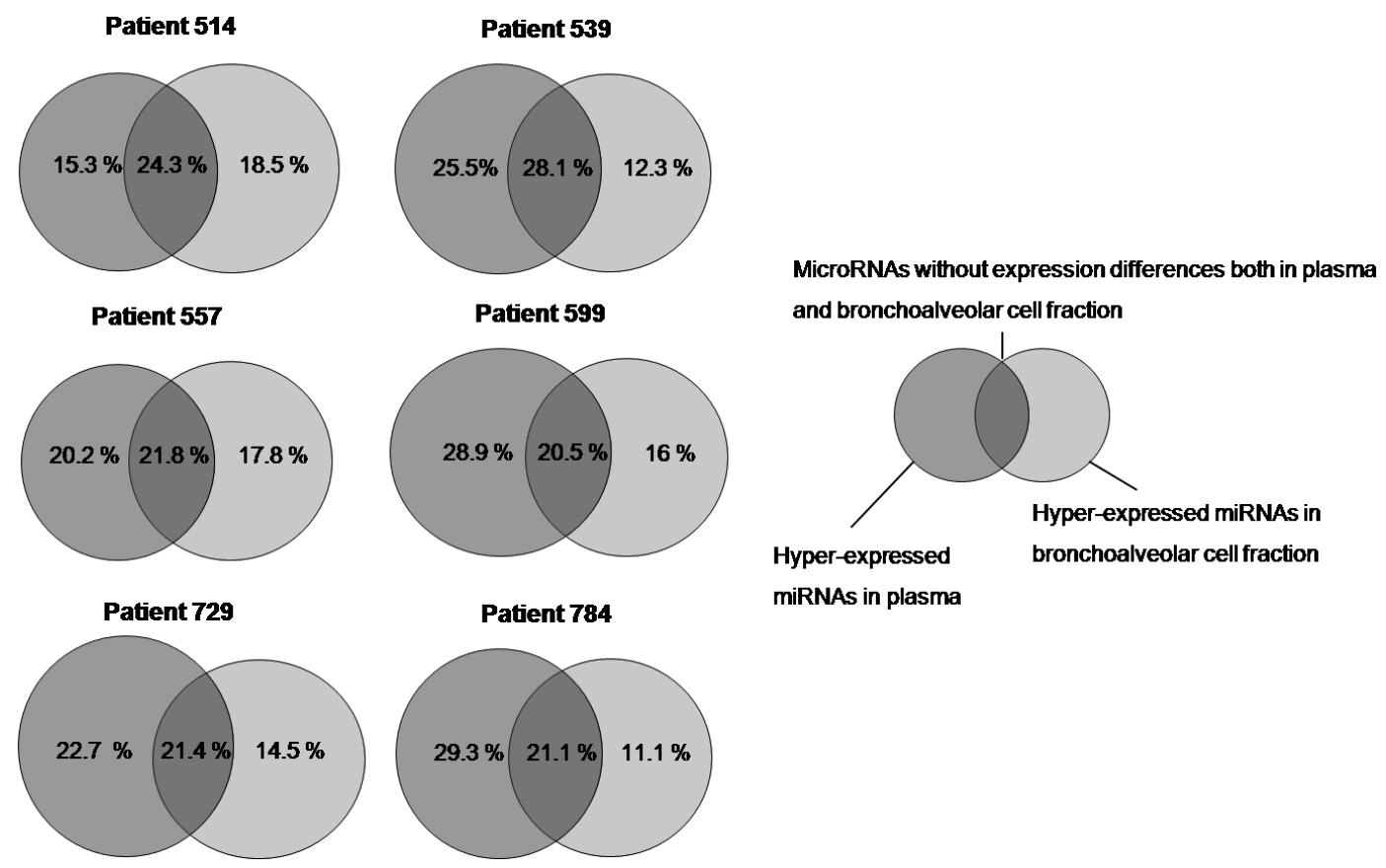

Fig. S4. Percentage of miRNA expression in plasma versus bronchoalveolar cell fraction.

of the 381 miRNAs versus miR-16), we used to compare the relative miRNA expression levels in plasma and bronchoalveolar cell fraction [23,24]. Considering that levels of expression were similar within 5 fold differences, we found that only around $20 \%$ of miRNAs showed similar expression patterns between plasma and broncoalveolar fluid samples (Fig. 3; supplementary Fig. S4). Furthermore, this percentage of similarity is heterogeneous among the different patients. As shown in Fig. 4, between 15.7-28.1\% $(\mathrm{N}=60$ and $\mathrm{N}=107$, respectively) of miRNAs were detected both in plasma and bronchoalveolar cell fraction within a 5 fold expression level differences, whereas a percentage from $11.1 \%(\mathrm{~N}=42)$ to $31.5 \%(\mathrm{~N}=120)$ of miRNAs were hyper-expressed in bronchoalveolar cell fraction and a percentage between 15-29.3\% (N $=57$ and $\mathrm{N}=111$, respectively) of miRNAs were hyper-expressed in plasma. Table 2 illustrates miRNAs that are co-ordinately regulated at least in 8 patients in plasma or bronchoalveolar cytology. We found four miRNAs (miR-17, miR-19b, miR-195 and miR-20b) with similar expression in both biological samples in $100 \%$ of patients. Therefore, these analyzed miRNAs in blood could serve as noninvasively prognosis predictors of respiratory diseases. Likewise, 28 miRNAs showed similar expression in $80 \%$ of studied patients. Taking a closer look at the 28 co-ordinately regulated miRNAs in plasma and bronchoalveolar cytology, we found that these miRNAs do not show significant expression differences in lung adenocarcinoma patients compared to the group without lung cancer (data not shown). However, for this type of analysis our sample size is small and results would need to be confirmed in a larger cohort. In the present study, our aim was to compare the miRNA expression levels in two biological samples with different grades of invasiveness, in order to validate their applicability as a source of biomarkers in respiratory diseases.

Our data indicate that, the profiles are not comparable. However, there is a similarity in the relative expression in a small subset of miRNAs between both biological samples.

\section{Discussion}

The potential identification of circulating plasma miRNAs as good biomarkers could provide an accurate way for the diagnosis of respiratory pathologies. However, our data reflects that there is an absence of association between expression pattern in the circulating plasma miRNAs and the bronchoalveolar cell fractionderived miRNAs from the same patient. Only a small subset of miRNAs (from $15 \%$ to $28 \%$ ) is commonly observed in both samples, and this considering below 5 fold differences in the expression levels. These results 
Table 2

Expression of miRNAs in both studied samples

\begin{tabular}{|c|c|c|}
\hline $\begin{array}{l}\text { Hyper-expressed miRNAs in } \\
\text { plasma }\end{array}$ & $\begin{array}{l}\text { Hyper-expressed miRNAs in } \\
\text { bronchoalveolar cell fraction }\end{array}$ & $\begin{array}{l}\text { Without differences between bronchoalveolar } \\
\text { cell fraction versus plasma }\end{array}$ \\
\hline $\begin{array}{l}\text { - In all studied samples: U6, miR- } \\
\text { 122, miR-133b, miR-134, miR-139- } \\
\text { 3p, miR-370, miR-485-3p, miR-493, } \\
\text { miR-758 } \\
\text { - At least in eight studied sam- } \\
\text { ples: RNU48, miR-1, miR-127-3p, } \\
\text { miR-146b-5p, miR-155, miR-199a- } \\
\text { 5p, miR-200b, miR-326, miR-337, } \\
\text { miR-375, miR-376a, miR-379, miR- } \\
\text { 382, miR-409-5p, miR-410, miR- } \\
\text { 411, miR-429, miR-433, miR-499a, } \\
\text { miR-487b, miR-495, miR-539, miR- } \\
\text { 654-3p, miR-655, miR-874, miR-889 }\end{array}$ & $\begin{array}{l}\text { - In all studied samples: RNU44, miR- } \\
\text { 200a, miR-205, miR-31, miR-34c-5p } \\
\text { - At least in eight studied samples: } \\
\text { miR-126, miR-193a-3p, miR-221, } \\
\text { miR-323-3p, miR-328, miR-423-5p, } \\
\text { miR-484, miR-518b, miR-708, miR- } \\
\text { 92a }\end{array}$ & $\begin{array}{l}\text { - In all studied samples: miR-17, miR-19b, } \\
\text { miR-195, miR-20b } \\
\text { - At least in eight studied samples: let- } \\
\text { 7b, let-7g, miR-106a, miR-106b, miR-10a, } \\
\text { miR-140-3p, miR-19a, miR-191, miR-192, } \\
\text { miR-20a, miR-222, miR-24, miR-25, miR- } \\
\text { 26b, miR-30b, miR-30c, miR-324-3p, miR- } \\
\text { 324-5p, miR-339-3p, miR-454, miR-532- } \\
\text { 3p, miR-532-5p, miR-590-5p, miR-886-5p }\end{array}$ \\
\hline
\end{tabular}

indicate that marker profiles from different tissues have to be carefully considered before using as biomarkers of respiratory diseases.

One limitation of this study is the sample size. However, it is important to highlight that our results clearly demonstrate that levels of miRNA expression are consistent in all studied patients. In addition, miRNA differences in expression were analyzed between biological specimens of the same patient. Therefore, probabilistic causation that the miRNA profiles are not comparable between plasma and bronchoalveolar fluid cytology is higher in a larger sample size.

We have found that the analysis of individual miRNA expression levels differs between both biological samples and there is a group of miRNAs characteristic to each sample. Thus, these differences of expression in circulating plasma miRNAs could be associated to communication processes between several organs, since exosomes containing microRNAs can be transferred to another cell and be functional in a different environment from that of origin [25-27].

$\mathrm{Hu}$ et al. have recently reported that the expression of four miRNAs (miR-1, miR-30d, miR-486, and miR499) in serum were significantly associated with overall survival of lung cancer [28]. Therefore, these miRNAs analyzed in serum could serve as noninvasive predictors for prognosis of this tumor. Nevertheless, these results need to be validated in other cohorts to evaluate their clinical application. Interestingly, we have found an increased relative expression of 18 miRNAs in 381 analyzed miRNAs (let-7g, miR-106a, miR-17, miR19a, miR-19b, miR-191, miR-20a, miR-222, miR-223, miR-24, miR-26a, miR-26b, miR-30b, miR-30c, miR320, miR-342, miR-484, and miR-93) both in plasma and bronchoalveolar cell fraction of all patients (data not shown). Therefore, this similarity of miRNA relative expression between biological samples may be associated with physiological condition in the respiratory system, although more studies are necessary to establish a functional role of these miRNAs.

It was reported that 12 miRNAs (miR-17-3p, miR21, miR-106a, miR-146, miR-155, miR-191, miR-192, miR-203, miR-205, miR-210, miR-212, and miR-214) are hyper-expressed in lung cancer tissues versus noncancerous lung tissues [29]. These 12 miRNAs isolated from plasma samples were shown to have significant expression differences in lung adenocarcinoma patients compared to a control group without lung cancer [30]. Recently, it was reported a similar expression of five miRNAs (miR-21, miR-126, miR-182, miR-210, and miR-486-5p) in paired surgical tissue and plasma specimens in non-small-cell lung cancer patients. These miRNAs has been identified with an aberrant expression in primary lung tumours [31]. In our study, there is no variability in the expression levels of these described miRNAs between plasma and bronchoalveolar cell fraction. This absence of association might be due to that, besides the small cohort used, our study is realized in patients with advanced lung adenocarcinoma. Despite large lack of correlation, four miRNAs (miR17, miR-19b, miR-195 and miR-20b) are expressed in both samples from the same patient without expression differences. However, these miRNAs have not been described as potential biomarkers for lung cancer.

In summary, this is the first study that describes the comparison of miRNA patterns between plasma and bronchoalveolar cell fraction in the same patient. We conclude that there is a clear lack of association of miRNA signatures between plasma and bronchoalveolar cytology. Furthermore, the variations among dif- 
ferent patients suggest that the miRNAs profiles obtained from different tissue samples have to be carefully validated in large cohorts before proper clinical application.

\section{Acknowledgements}

We thank A. Salinas and R. Melendez for their continuous technical support. LPA is funded by Proyecto de Excelencia de la Consejería de Innovación, Ciencia y Empresa, Junta de Andalucía (P08-CVI-04090), Fondo de Investigación Sanitaria (PI081156) and the Roche Fellowship in 75th Anniversary, Spain. SMP is funded by Fundación Científica de la Asociación Española Contra el Cáncer, Consejería de Salud, Servicio Andaluz de Salud (PI-0224/2009), and Fundación Mutua Madrileña (2009). AN is funded by the Portuguese Minister of Science, Technology and Superior Education-FCT (Fundação para a Ciência e para a Tecnologia: SFRH/ BD/ 48341/ 2008).

\section{Disclosure/conflict of interest}

The authors declare no conflict of interest.

\section{References}

[1] E.A. Hirschowitz, Biomarkers for lung cancer screening: interpretation and implications of an early negative advanced validation study, Am J Respir Crit Care Med 179 (2009), 1-2.

[2] C. Auffray, I.M. Adcock, K.F. Chung, R. Djukanovic, C. Pison and P.J. Sterk, An integrative systems biology approach to understanding pulmonary diseases, Chest 137 (2010), 14101416.

[3] C.L. Bartels and G.J. Tsongalis, MicroRNAs: novel biomarkers for human cancer, Clin Chem 55 (2009), 623-631.

[4] V. Ambros, The functions of animal microRNAs, Nature 431 (2004), 350-355.

[5] I. Bentwich, A. Avniel, Y. Karov, R. Aharonov, S. Gilad, O. Barad, A. Barzilai, P. Einat, U. Einav, E. Meiri, E. Sharon, Y. Spector and Z. Bentwich, Identification of hundreds of conserved and nonconserved human microRNAs, Nat Genet 37(2005), 766-770.

[6] C.Z. Chen, L. Li, H.F. Lodish and D.P. Bartel, MicroRNAs modulate hematopoietic lineage differentiation, Science $\mathbf{3 0 3}$ (2004), 83-86.

[7] P. Sood, A. Krek, M. Zavolan, G. Macino and N. Rajewsky, Cell-type-specific signatures of microRNAs on target mRNA expression, Proc Natl Acad Sci USA 103(2006), 2746-2751.

[8] P. Landgraf, M. Rusu, R. Sheridan, A. Sewer, N. Iovino, A. Aravin, S. Pfeffer, A. Rice, A.O. Kamphorst, M. Landthaler, C. Lin, N.D. Socci, L. Hermida, V. Fulci, S. Chiaretti, R. Foà, J. Schliwka, U. Fuchs, A. Novosel, R.U. Müller, B. Schermer, U. Bissels, J. Inman, Q. Phan, M. Chien, D.B. Weir, R. Choksi,
G. De Vita, D. Frezzetti, H.I. Trompeter, V. Hornung, G. Teng, G. Hartmann, M. Palkovits, R. Di Lauro, P. Wernet, G. Macino, C.E. Rogler, J.W. Nagle, J. Ju, F.N. Papavasiliou, T. Benzing, P. Lichter, W. Tam, M.J. Brownstein, A. Bosio, A. Borkhardt, J.J. Russo, C. Sander, M. Zavolan and T. Tuschl, A mammalian microRNA expression atlas based on small RNA library sequencing, Cell 129 (2007), 1401-1414.

[9] J.R. Neilson, G.X. Zheng, C.B. Burge and P.A. Sharp, Dynamic regulation of miRNA expression in ordered stages of cellular development, Genes Dev 21 (2007), 578-579.

[10] D.P. Bartel, MicroRNAs: genomics, biogenesis, mechanism, and function, Cell 116 (2004), 281-297.

[11] K.R. Chien, Molecular medicine: microRNAs and the tell-tale heart, Nature 447 (2007), 389-390.

[12] M. Fabbri, M. Ivan, A. Cimmino, M. Negrini and G.A. Calin, Regulatory mechanisms of microRNAs involvement in cancer, Expert Opin Biol Ther 7 (2007), 1009-1019.

[13] W.J. Lukiw, Micro-RNA speciation in fetal, adult and Alzheimer's disease hippocampus, Neuroreport 18 (2007), 297-300

[14] A.E. Williams, H. Larner-Svensson, M.M. Perry, G.A. Campbell, S.E. Herrick, I.M. Adcock, J.S. Erjefalt, K.F. Chung and M.A. Lindsay, MicroRNA expression profiling in mild asthmatic human airways and effect of corticosteroid therapy, PLoS One 4 (2009), e5889.

[15] Y. Xi, G. Nakajima, E. Gavin, C.G. Morris, K. Kudo, K. Hayashi and J. Ju, Systematic analysis of microRNA expression of RNA extracted from fresh frozen and formalin-fixed paraffin-embedded samples, RNA 13 (2007), 1668-1674.

[16] A. Liu, M.T. Tetzlaff, P. Vanbelle, D. Elder, M. Feldman, J.W. Tobias, A.R. Sepulveda and X. Xu, MicroRNA expression profiling outperforms mRNA expression profiling in formalinfixed paraffin-embedded tissues, Int J Clin Exp Pathol 2 (2009), 519-527.

[17] X. Chen, Y. Ba, L. Ma, X. Cai, Y. Yin, K. Wang, J. Guo, Y. Zhang, J. Chen, X. Guo, Q. Li, X. Li, W. Wang, Y. Zhang, J. Wang, X. Jiang, Y. Xiang, C. Xu, P. Zheng, J. Zhang, R. Li, H. Zhang, X. Shang, T. Gong, G. Ning, J. Wang, K. Zen, J. Zhang, C.Y. Zhang, Characterization of microRNAs in serum: a novel class of biomarkers for diagnosis of cancer and other diseases, Cell Res 18 (2008), 997-1006.

[18] Y. Xie, N.W. Todd, Z. Liu, M. Zhan, H. Fang, H. Peng, M. Alattar, J. Deepak, S.A. Stass and F. Jiang, Altered miRNA expression in sputum for diagnosis of non-small cell lung cancer, Lung Cancer 67 (2010), 170-176.

[19] D. Zubakov, A.W. Boersma, Y. Choi, P.F. van Kuijk, E.A. Wiemer and M. Kayser, MicroRNA markers for forensic body fluid identification obtained from microarray screening and quantitative RT-PCR confirmation, Int J Legal Med 124 (2010), 217-226.

[20] P.S. Mitchell, R.K. Parkin, E.M. Kroh, B.R. Fritz, S.K. Wyman, E.L. Pogosova-Agadjanyan, A. Peterson, J. Noteboom, K.C. O'Briant, A. Allen, D.W. Lin, N. Urban, C.W. Drescher, B.S. Knudsen, D.L. Stirewalt, R. Gentleman, R.L. Vessella, P.S. Nelson, D.B. Martin, M. Tewari, Circulating microRNAs as stable blood-based markers for cancer detection, Proc Natl Acad Sci U S A 105 (2008), 10513-10518.

[21] M. Mraz, K. Malinova, J. Mayer and S. Pospisilova, MicroRNA isolation and stability in stored RNA samples, Biochem Biophys Res Commun 390 (2009), 1-4.

[22] E.M. Kroh, R.K. Parkin, P.S. Mitchell and M. Tewari, Analysis of circulating microRNA biomarkers in plasma and serum using quantitative reverse transcription-PCR (qRT-PCR), Methods $\mathbf{5 0}$ (2010), 298-301. 
[23] K.J. Livak and T.D. Schmittgen, Analysis of relative gene expression data using real-time quantitative PCR and the 2(Delta Delta C(T)) Method, Methods 25 (2001), 402-408.

[24] T.D. Schmittgen and K.J. Livak, Analyzing real-time PCR data by the comparative C(T) method, Nat Protoc 3 (2008), 1101-1108.

[25] M.P. Hunter, N. Ismail, X. Zhang, B.D. Aguda, E.J. Lee, L. Yu, T. Xiao, J. Schafer, M.L. Lee, T.D. Schmittgen, S.P. NanaSinkam, D. Jarjoura and C.B. Marsh, Detection of microRNA expression in human peripheral blood microvesicles, PLoS One 3 (2008), e3694.

[26] E. Pap, E. Pállinger, M. Pásztói and A. Falus, Highlights of a new type of intercellular communication microvesicle-based information transfer review, Inflamm Res 58 (2009),1-8.

[27] R.J. Simpson, J.W. Lim, R.L. Moritz and S. Mathivanan, Exosomes: proteomic insights and diagnostic potential, Expert Review of Proteomics 6 (2009), 267-283.
[28] Z. Hu, X. Chen, Y. Zhao, T. Tian, G. Jin , Y. Shu , Y. Chen, L. Xu, K. Zen, C. Zhang and H. Shen. Serum microRNA signatures identified in a genome-wide serum microRNA expression profiling predict survival of non-small-cell lung cancer, $\mathrm{J}$ Clin Oncol 28 (2010), 1721-1726.

[29] N. Yanaihara, N. Caplen, E. Bowman, M. Seike, K. Kumamoto, M. Yi, R.M. Stephens, A. Okamoto, J. Yokota, T. Tanaka, G.A. Calin, C.G. Liu, C.M. Croce and C.C. Harris, Unique microRNA molecular profiles in lung cancer diagnosis and prognosis, Cancer Cell 9 (2006), 189-198.

[30] G. Rabinowits, C. Gerçel-Taylor, J.M. Day, D.D. Taylor and G.H. Kloecker, Exosomal microRNA: a diagnostic marker for lung cancer, Clin Lung Cancer 10 (2009), 42-46.

[31] J. Shen, N.W. Todd, H. Zhang, L. Yu, X. Lingxiao, Y. Mei, M. Guarnera, J. Liao, A. Chou, C.L. Lu, Z. Jiang, H. Fang, R.L. Katz and F. Jiang, Plasma microRNAs as potential biomarkers for non-small-cell lung cancer, Lab Invest 91 (2011), 579-587. 


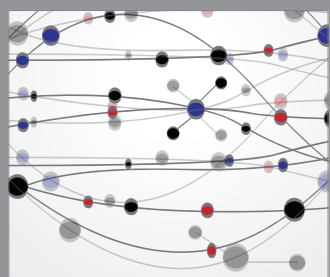

The Scientific World Journal
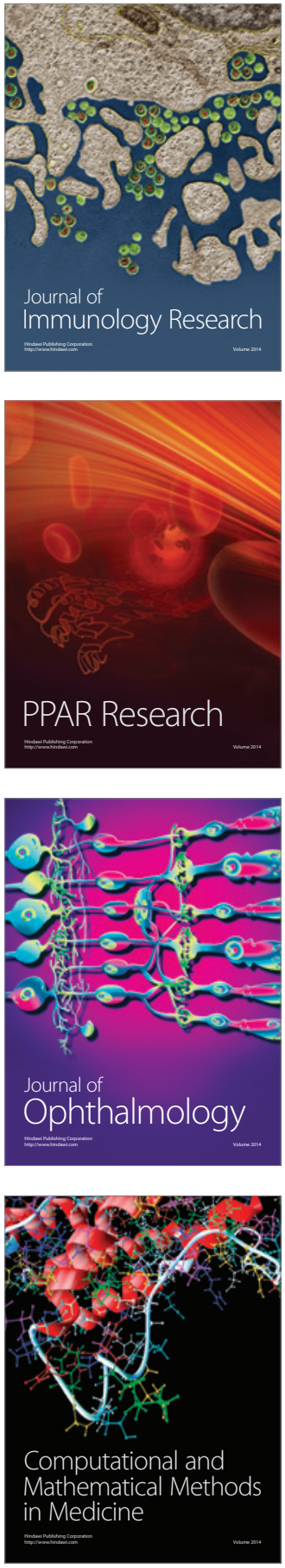

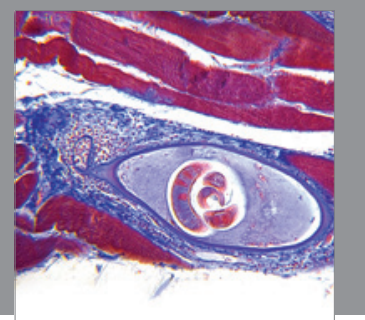

Gastroenterology

Research and Practice
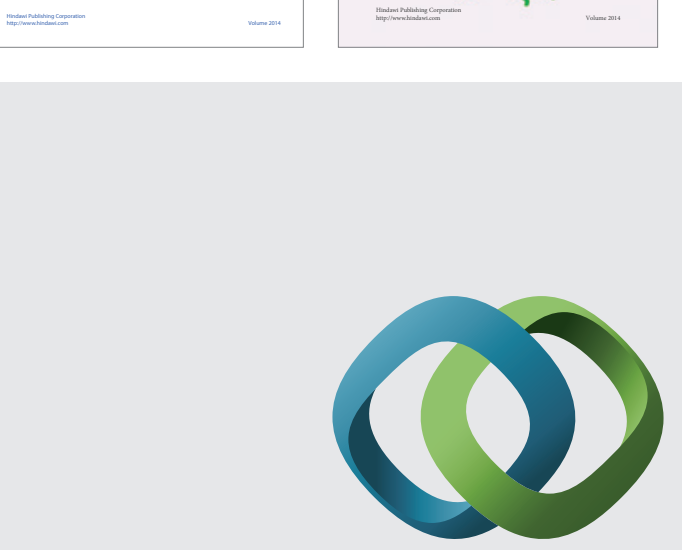

\section{Hindawi}

Submit your manuscripts at

http://www.hindawi.com
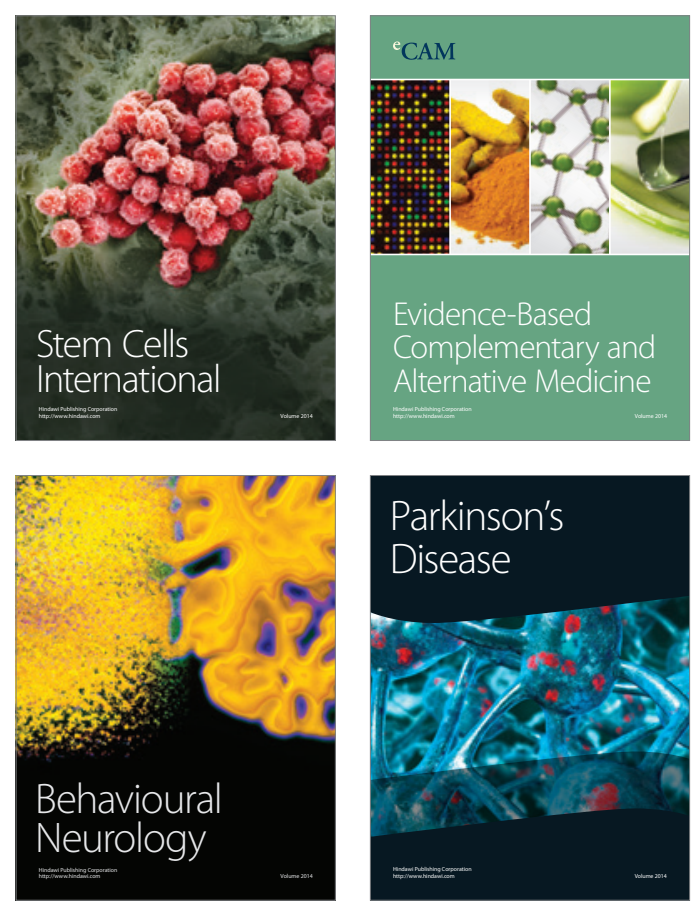

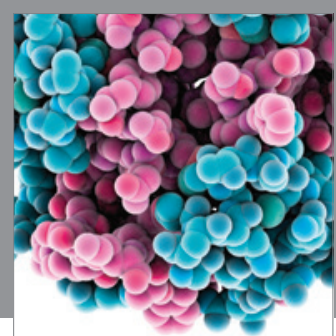

Journal of
Diabetes Research

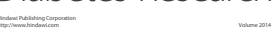

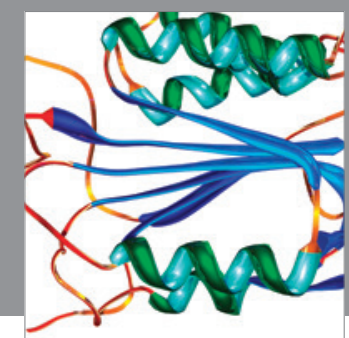

Disease Markers
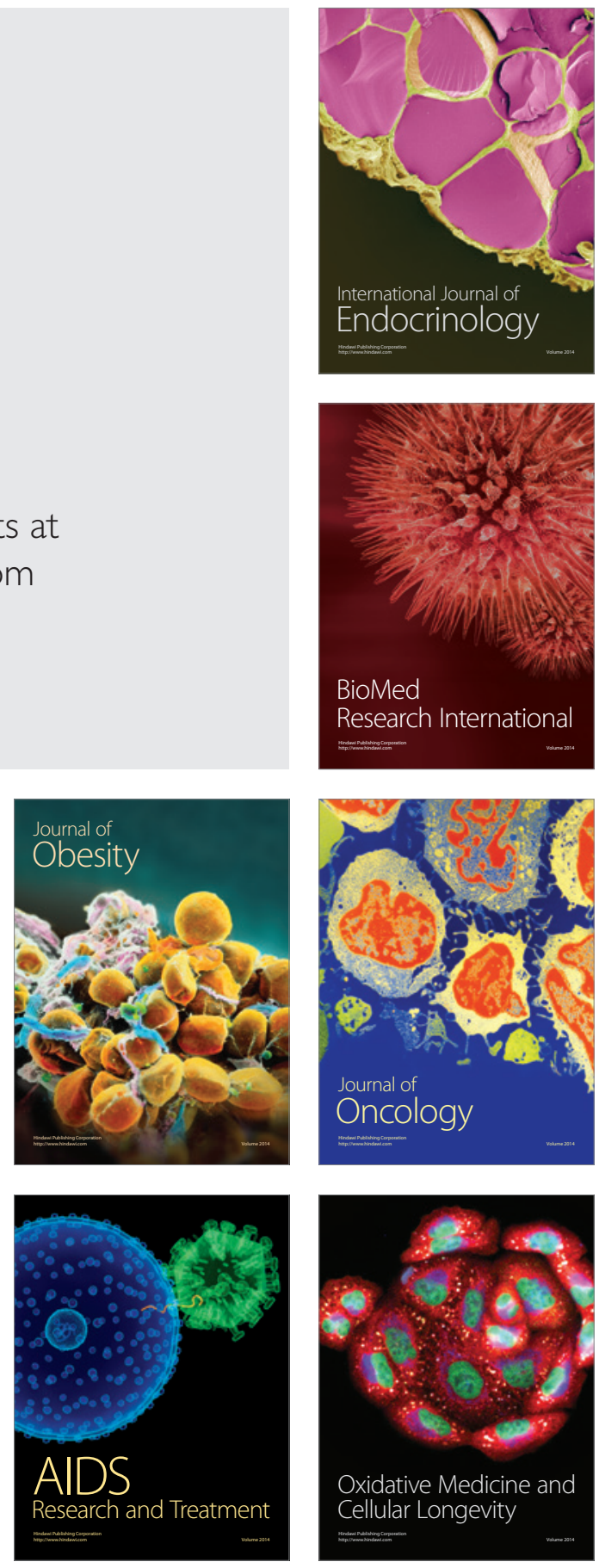